\title{
Assessment of visual acuity after primary vitrectomy with internal limiting membrane peeling for macula off retinal detachment
}

\author{
Islam Awny ${ }^{1}$, Mohamed Anber ${ }^{1}$, Mohammad Hussein Mousa ${ }^{1}$, Hassan Ali \\ Mourtada ${ }^{2}$ \\ 1- Department of ophthalmology, Sohag faculty of medicine, Sohag \\ University, Sohag \\ 2- Department of ophthalmology, Kasr El Ainy faculty of medicine, Cairo \\ University, Cairo
}

\begin{abstract}
Purpose: to assess the visual result after primary vitrectomy with internal limiting membrane peeling for macula off retinal detachment.

Patients and methods: this was a prospective comparative uncontrolled case series. The study included 30 eyes with rhegmatogenous retinal detachment with macula off, the case were classified into two groups; group A 15 eyes subjected to primary vitrectomy without internal limiting membrane peeling and group B eyes subjected to primary vitrectomy with internal limiting membrane peeling. Assessment of best corrected visual acuity after removal of silicone oil had been done.

Results: this study included 30 eyes of 30 patients, 16 (53.33\%) were males and 14 $(46.67 \%)$ were females, the mean age of studied patients was $(43.37 \pm 10.40)$ years old. There was no statistically significant difference in mean $\operatorname{logMAR}$ BCVA after silicone oil removal $(1.18 \pm 0.29$ for group $\mathrm{A}$ versus $0.99 \pm 0.38$ for group $\mathrm{B} ; \mathrm{P}=$ 0.12 ).

Conclusion: primary vitrectomy with ILM peeling showed no superiority in visual results over primary vitrectomy without LIM peeling for macula off retinal detachment.

Keywords: Vitrectomy, internal limiting membrane, rhegmatogenous retinal detachment.

Assessment of visual acuity after primary vitrectomy with internal limiting membrane peeling for macula off retinal detachment

Islam Awny, Mohamed Anber, Mohammad Hussein Mousa, Hassan Ali Mourtada
\end{abstract}

\section{Introduction}

Retinal detachment is the term used to describe detachment of the neurosensory retina from the underlying membrane, the retinal pigment epithelium. The separation of the two layers takes place within the fissure formed by the invagination of the optic cup ${ }^{1}$.

There are three types of retinal detachment according to causative mechanisms. Rhegmatogenous retinal detachments (RRD) are the most common. They are caused by breaks in the neurosensory retina, some of which are associated with 'vitreoretinal traction', resulting in liquefied vitreous entering the subretinal space ${ }^{2}$.

A proportion of patients with retinal detachment will be asymptomatic. Those who are asymptomatic usually have very peripheral or inferior detachments that progress slowly ${ }^{3}$. Most commonly, patients with retinal detachment are aware of a dark shadow progressing across the visual field from the periphery, with rapid loss of acuity as the macula becomes 
involved. Others may notice sudden loss of vision. Occasionally flashing lights are associated with retinal detachment and are often bright and multicoloured and seen over the whole visual field. They may occur only once and may be associated with a single sharp pain ${ }^{4}$.

Using the 90D lens, indirect biomicroscopy should be performed in order to look for any retinal breaks or areas of retinal detachment. The posterior pole should be assessed to determine if there is any involvement of the macula. The retinal periphery should be examined in the nine cardinal positions of gaze ${ }^{5}$.

Repair of primary rhegmatogenous retinal detachment (RRD) was usually unsuccessful before Gonin 6 demonstrated the importance of localizing and sealing retinal breaks. Scleral buckling introduced by Custodis ${ }^{7}$ intraocular gases introduced by Norton ${ }^{8}$ and the development of vitreous surgery by Machemer 9 profoundly changed the history of RRD repair. The initial device was a 17-gauge $(1.42 \mathrm{~mm})$ instrument that combined a vitreous cutter, infusion, and aspiration, and utilized $2.3 \mathrm{~mm}$ scleral incision ${ }^{10}$. As 20-gauge PPV became more widely used, a number of complications became apparent. A major problem was the development of iatrogenic retinal breaks, specifically those at the sclerotomy site ${ }^{11}$. The initial set of 25-gauge instruments developed by de Juan and Hickingobtham contained only a pneumatic vitrector, scissors, and a membrane removal instrument for use in pediatric eyes ${ }^{12}$. A 23-gauge vitrectomy probe was introduced in 1990 by Peyman, although its intended application was limited to vitreous and retinal biopsy ${ }^{13}$.

Diamond dusted silicone tipped cannula (Tano's scraper) can be used to create an edge. When a well-defined edge of a ILM can be visualized, the edge of the membrane is explored with a membrane pick, until the edge is elevated; it is usually then possible to grasp it with a membrane forceps. This tissue is then gently stripped away from the retina. If the membrane is tightly adherent to the retina, regrasping the membrane and gently stripping from several points will help in membrane removal. These multiple "regraspings" should take place as close to the membraneretina interface as possible. Sometimes a surgeon notes that the retina is becoming elevated away from the retinal pigment epithelium (RPE). At this point, the membrane should be re-engaged at another site and a different directional vector force used to strip the membrane ${ }^{14}$.

\section{Patients and methods:}

This was a Prospective comparative uncontrolled case series. The study enrolled 30 eyes with rhegmatogenous retinal detachment with macula off subjected to primary vitrectomyat Sohag University Hospital, Sohag, Egypt and Dar AlOuyn Hospital, Cairo, Egypt.

The study was approved by the medical ethics committee of the faculty of medicine, Sohag University. The Declaration rules of Helsinki were respected throughout our study, and written informed consent was obtained from all patients for the treatment sequence.

Patients will be excluded from participating in the study if one or more of the following criteria were found; previous vitreous surgery, previous glaucoma filtration surgery, patients with inadequate follow up, macular hole retinal detachment and Patients with grade C PVR.

All patients were interviewed and underwent ophthalmologic 
SOHAG MEDICAL JOURNAL

Vol. 21 No.2 July 2017
Assessment of visual acuity after primary vitrectomy Islam Awny. Et al examinations both preoperatively and postoperatively. Examinations included best corrected visual acuity in LogMAR.

Data were collected concerning the length of time between the last operation and the silicone oil removal, duration of the follow-up period after silicone oil removal, and number and type of operations.

Patients were classified into 2 groups, Group A cases subjected to primary vitrectomy without internal limiting membrane peeling and group B cases subjected to primary vitrectomy, with internal limiting membrane peeling, Patients of both groups received a post operative treatment consisting of antibiotics eye drops for 4 weeks and steroids.

All patients were followed up for 6 months. Patients were seen on the first post operative day, then on the first and third week, and then every month.

\section{Results}

This study included 30 eyes of 30 patients, $16(53.33 \%)$ were males and $14(46.67 \%)$ were females, the mean age of studied patients was $(43.37 \pm 10.40)$ years old.

Females were $5(33.33 \%)$ patients in group A and $9(60.00 \%)$ patients in group B, while males were $10(66.67 \%)$ patients in group A and $6(40.00 \%)$ patients in group $\mathrm{B}(\mathrm{P}=0.14)$. there was no statistically significant difference between the average age for both groups $(50.07 \pm 10.87$ in group $\mathrm{A}$ versus $56.67 \pm 9.09$ in group $\mathrm{B} ; \mathrm{P}=$ 0.08)table1.

There was no significant difference according to the extent of retinal detachment between both group, table 2 .

Table 1 Preoperative data of studied population

\begin{tabular}{|c|c||c||c|}
\hline Variables & $\begin{array}{c}\text { Group (A): without } \\
\text { ILM peeling }\end{array}$ & $\begin{array}{c}\text { Group (B): with ILM } \\
\text { peeling }\end{array}$ & P value \\
\hline \hline Age/years & $50.07 \pm 10.87$ & $56.67 \pm 9.09$ & \\
Mean \pm SD & $50(25-70)$ & $60(40-67)$ & 0.08 \\
Median (range) & $5(33.33 \%)$ & $9(60.00 \%)$ & 0.14 \\
\hline \hline Gender & $10(66.67 \%)$ & $6(40.00 \%)$ & \\
Females & & & \\
Males & &
\end{tabular}

Table 2: Comparison between the two groups as regard extend of RD

\begin{tabular}{|c||c||c||c||}
\hline Variables & $\begin{array}{c}\text { Group (A): without } \\
\text { ILM peeling }\end{array}$ & $\begin{array}{c}\text { Group (B): with ILM } \\
\text { peeling }\end{array}$ & P value \\
\hline \hline Extend of RD & & & \\
One quadrant & $1(6.67 \%)$ & 0 & 0.30 \\
Two quadrants & $7(46.67 \%)$ & $6(40.00 \%)$ & \\
Three quadrants & $3(20.00 \%)$ & $4(26.67 \%)$ & \\
Four quadrants & $4(26.67 \%)$ & $5(33.33 \%)$ & \\
\hline
\end{tabular}


SOHAG MEDICAL JOURNAL

Vol. 21 No.2 July 2017

There was no statistically significant difference in mean $\operatorname{logMAR}$ BCVA after silicone oil removal $(1.18 \pm 0.29$ for group A versus $0.99 \pm 0.38$ for group $\mathrm{B} ; \mathrm{P}=$ 0.12 ), table 3 and figure 1.

Figure 1: Comparison between the two groups as regard $\operatorname{logMAR} B C V A$ after SOR

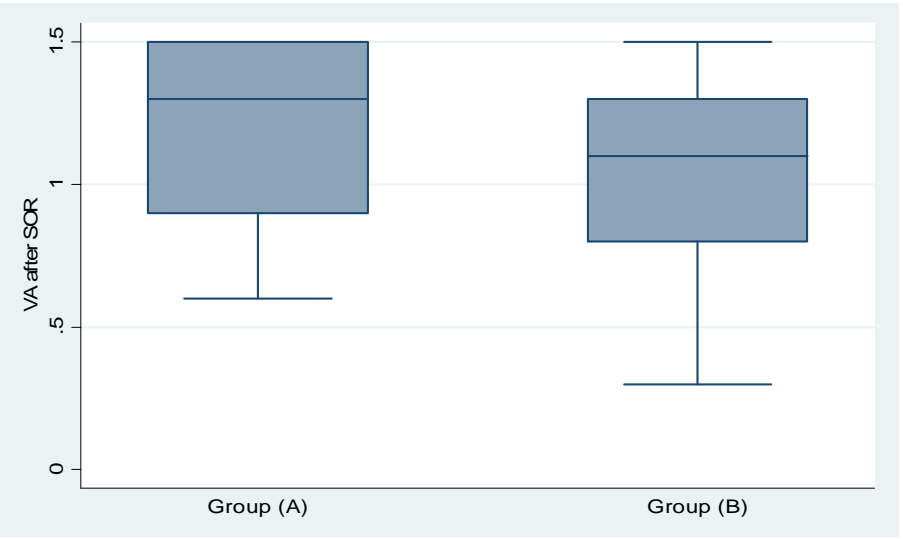

Table 3: Comparison between the two groups as regard logMAR BCVA

\begin{tabular}{|c|c||c||c||}
\hline Variables & $\begin{array}{c}\text { Group (A): } \\
\text { without ILM } \\
\text { peeling }\end{array}$ & $\begin{array}{c}\text { Group (B): with } \\
\text { ILM peeling }\end{array}$ & P value \\
\hline \hline $\begin{array}{c}\text { visual acuity after SOR } \\
\text { Mean } \pm \text { SD }\end{array}$ & $1.18 \pm 0.29$ & $0.99 \pm 0.38$ & \multirow{2}{*}{0.12} \\
Median (range) & $1.3(0.6-1.5)$ & $1.1(0.3-1.5)$ & \\
\hline \hline visual acuity after SOR & & & \\
& & $2(13.33 \%)$ & \multirow{2}{*||}{0.76} \\
0.3 & 0 & $1(6.67 \%)$ & \\
0.6 & $1(6.67 \%)$ & $2(13.33 \%)$ & \\
0.8 & $1(6.67 \%)$ & $1(6.67 \%)$ & \\
0.9 & $2(13.33 \%)$ & $1(6.67 \%)$ & \\
1.1 & $1(6.67 \%)$ & $1(20.00 \%)$ & \\
1.2 & $1(6.67 \%)$ & $2(13.33 \%)$ & \\
1.3 & $1(6.67 \%)$ & $2(13.33 \%)$ & \\
1.5 & $4(26.67 \%)$ & & \\
\hline
\end{tabular}

\section{Discussion}

Studying the pre operative factors, we found that extent of retinal detachment, number of breaks, and status of the lens were insignificant for the development of epiretinal membrane, extent of retinal detachment was (one quadrant detachment was 1 eye "6.67 $\% "$ in group A and zero eye in group $\mathrm{B}$, two quadrants detachment was 7 eyes "46.67 \%" in group A and 6 eye "40.00\%" in group B, three quadrants detachment was 3 eyes "20.00\%" and 4 eyes "26.67 \%", and four quadrants detachment was 4 eyes "26.67 \%" in group A and 5 eyes "33.33 \%" in group B. $\mathrm{P}=0.3$ ), number of breaks (one break in 8 eyes "53.33 \%" in group A and 5 eyes " $33.33 \% "$ in group B, two 
breaks in 5 eyes " $33.33 \%$ " in group A and 8 eyes "53.33\%" in group $\mathrm{B}$, and three breaks in 2 eyes "13.33 \%" in group A and 2 eyes " $13.33 \%$ " in group B. $P=0.5$ ), and status of lens was (it was clear in 7 eyes "46.67 \%" in group A and 10 eyes "66.67 \%" in group B, cataractus in 6 eyes "40.00\%" in group A and 10 eyes "66.67 \%" in group B, and pseudophakic in 2 eyes "13.33\%" in group $\mathrm{A}$ and zero eye in group $\mathrm{B}$. $\mathrm{P}$ $=0.27$ ).

Similar observations reported by Martínez-Castillo $\mathrm{V}^{15}$, this study done on 312 eyes of 307 patients and 28 of the 312 eyes "8.97 \%" developed epiretinal membrane during the post operative period, pre operative risk factors in this study were insignificant. Extent of retinal detachment was (in ERM group one quadrant in 12 "4\%", two quadrants in 101 eyes "36 \%", three quadrants in 107 eyes "38 \%", and four quadrants in 64 eyes "23\%", and in non - ERM group one quadrant in 3 eyes "11\%", and two quadrants in 10 eyes "36 \%", three quadrants in 9 eyes "32 \%", and four quadrants in 6 eyes "21 \%".P = 0.483). Number of breaks was (in ERM group single break in 160 eyes "56 \%" and multiple breaks in 124 eyes "44\%", and in non - ERM group single break in 15 eyes "54 \%" and multiple breaks in 13 eyes "46\%". P = 0.778). status of the lens was (in ERM group Aphakia in 17 eyes "6\%" and pseudophakia in 267 eyes "94 \%" and in non - ERM group Aphakia in 0 "0 \%" and 28 eyes "100 $\% " . \mathrm{P}=0.183$ ).

According to visual acuity there was general improvement in the mean logMAR BCVA in cases with ILM peeling than other cases without ILM peeling, although there was no statistically significant difference in the mean logMAR BCVA in both groups, which may be explained by pre operative macular detachment that decreased the net result of visual improvement.

Another study done by Dominik O. et $\mathrm{al}^{16}$, showed general improvement in the mean logMAR BCVA but there was no significant statistical difference between group A without ILM peeling $(1.89 \pm 0.87)$ and group B with ILM peeling $(1.85 \pm 0.83) \mathrm{p}=0.6$.

Nam KY et $\mathrm{al}^{17}$ showed the overall visual acuity was better in the group with ILM peeling than that without ILM peeling, although the difference was not significant may be due to macular detachment. However when the macula - on group was analyzed, the mean visual acuity was better in the ILM peeling group than in the non ILM peeling group, and a significant difference was found at the 12 month follow up ( $p=0.03$ ). This showed that the visual acuity was affected by the epiretinal membrane that occurred after primary vitrectomy for rhegmatogenous retinal detachment, implying that removal of the ILM results in better visual acuity by preventing the occurrence of a post operative epiretinal membrane compared with patients who did not undergo ILM peeling.

Aras $C$ et al $^{18}$ reported that post operative visual acuity was generally better if the macula was not puckered, while there was no significant difference in the final visual acuity between the two groups.

\section{References}

1. Naumann G: Pathologie des Auges. 2nd ed. Berlin: Springer; 1997.

2. Kanski JJ. Clinical Ophthalmology, A Systematic Approach 5th Edition 2003. Pub: Butterworth Heinemann.

3. Scott JD. Surgery for Retinal and Vitreous Disease. 1998, Publisher: Butterworth-Heinemann.

4. Pocklinghorne PJ and Craig JP. Analysis of Symptoms associated with rhegmatogenous retinal detachments. 
SOHAG MEDICAL JOURNAL

Vol. 21 No.2 July 2017
Clinical and Experimental Ophthalmology, 1994. 32: 603-606.

5. Michael Colucciello. Rhegmatogenous Retinal Detachment. ISSN - 00913847, April 2009, No. 2, Volume 37.

6. Corcóstegui B, Adán A, García-Arumí J, Mateo C, Nieto I. Cirugía vitreoretiniana, indicaciones y técnicas. Madrid. Tecnimedia (Ed) 1999; 47-48.

7. Smiddy WE, Michels RG, Green WR. Lens and peripheral etinal relationships during vitrectomy. Retina 1991; 11(2): 199-203.

8. Guyer D, Yannuzzi L, Chang S, Shields J, Green R. Retina- Vitreous. Macula. Saunders Company 1999; 1312-13.

9. De Juan E Jr, Landers MB III. New technique for visualization infusion cannula during vitreous surgery. Am J Ophthalmol 1984;97:657.

10. Fabian, ID \& Moisseiev J. Sutureless vitrectomy: evolution and current practices. British Journal of Ophthalmology.Vol. 95, No. 3, (March 2011), pp.( 318-324).

11. Machemer R., \& Hickingbotham D. The three-port microcannular system for closed vitrectomy. Am J Ophthalmol, Vol. 100, (October 1985), pp. (590-592).

12.De Juan E. Jr \& Hickingbotham, D. Refinements in microinstrumentation for vitreous surgery. Am J Ophthalmol, Vol.109, No. 2, (Feb 1990), pp. (21820).
13.Peyman, GA. A miniaturized vitrectomy system for vitreous and retinal biopsy. Can J Ophthalmol, Vol. 25, No. 6, (Oct 1990), pp. (285-6).

14. Abrams GW, Gentile RC. Vitrectomy. In: Guyer DR, Yannuzzi LA, Chang S, Shields JA, Green WR, (Eds). RetinaVitreous- Macula, 1st edition. Philadelphia, Pennsylvania: WB Saunders; 1999;1298-1319.

15. Martínez-castillo V, Boixadera A, Boixadera L, et al. Epiretinal Membrane after Pars Plana Vitrectomy for Primary Psudophakic and Aphakic Rhegmatogenous Retinal Detachment, Incidence and outcomes. Retina, 32: 1350-1355; 2012.

16. Dominik O, Maciej B, Siawomir C, et al. Internal Limiting Membrane Peeling as Prophylaxis of Macular Pucker Formation in Eyes Undergoing Retinectomy for Severe Proliferative Vitreo Retinopathy. Retina, 32: 226-231; 2012.

17. Nam KY, Kim JY. Effect of Internal Limiting Membrane Peeling on the Development of Epiretinal Membrane after Pars Plana Vitrectomy for Primary Rhegmatogenous Retinal Detachment. Retina, 35: 880-885;2015.

18. Aras C, Arici C, Akar S, et al. Peeling of Internal Limiting Membrane During Vitrectomy for Complicated Retinal Detachment Prevents Epimacular Membrane Formation. Graefes Arch Clin Exp Ophthalmol, 247: 619-623; 2009. 